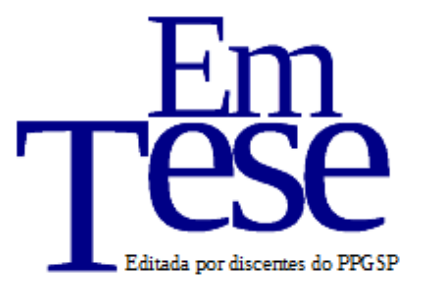

\title{
Formação de professores de ciências sociais/sociologia: subsídios para o debate
}

\author{
Leomir Souza Costa ${ }^{1}$
}

\section{Introdução}

Com a intensificação da luta nacional pela volta da Sociologia ao currículo escolar houve uma retomada dos temas relacionados à Sociologia da Educação como objeto de estudo no campo das Ciências Sociais e um reposicionamento das pesquisas sobre o ensino de Sociologia neste campo e no da Educação (NEUHOLD, 2014; HANDFAS; MAÇAÍRA, 2014), e nessa direção, veem-se ampliando as discussões e reflexões sobre a formação docente. Diante desse cenário, este texto busca refletir sobre uma problemática ainda pouco explorada nos estudos consagrados à Sociologia da Educacional, que diz respeito à formação inicial dos professores de Ciências Sociais/Sociologia ${ }^{2}$. Mesmo nem sempre tratada com a necessária relevância, a questão da formação de professores coloca-se como uma temática fecunda e instigante (CUNHA, 2013).

O retorno da obrigatoriedade do ensino de Sociologia nas três séries do ensino médio $^{3}$ tem provocado muitos debates no campo sociológico, pois trata-se de um novo

\footnotetext{
${ }^{1}$ Graduado em Ciências Sociais pela UFMA e mestrando do Programa de Pós-Graduação em Ciências Sociais da UFMA.

${ }^{2}$ Mesmo que a disciplina na educação básica seja Sociologia, entende-se que ainda não há, na comunidade dos cientistas sociais, um consenso em torno da nomenclatura mais aceitável (alguns reivindicam que deve ser Ciências Sociais, uma vez que representaria, de fato, as três ciências da área Antropologia, Ciência Política e Sociologia; outros defendem que deve permanecer da mesma forma), fato ratificado pelas denominações das duas principais instâncias, em nível nacional, que debatem a temática: a Associação Brasileira de Ensino de Ciências Sociais (ABECS) e o Encontro Nacional de Ensino de Sociologia na Educação Básica (ENESEB). Sem embarcar nessa discussão, todas as vezes que aparecer no texto as expressões "ensino de", "cursos de", "professores ou docentes de", acompanhadas dos nomes "Ciências Sociais" ou "Sociologia", o leitor deve compreender que as duas nomenclaturas estão sendo consideradas.

${ }^{3}$ Lei n ${ }^{\circ} 11.684$, de 02 de junho de 2008, aprovada a partir do Parecer n ${ }^{\circ} 38 / 2006$, do Conselho Nacional de Educação (CNE).
} 
locus, tanto de pesquisa quanto de atuação profissional. Se por um lado, a obrigatoriedade do ensino da disciplina em território nacional representou uma conquista, por outro, na busca por uma legitimidade escolar e social da disciplina, os desafios são enormes e variados (MORAES, 2009; SILVA, 2007; VELOSO, 2012). Um dos principais está relacionado ao processo formativo dos professores dessa disciplina nos cursos de Ciências Sociais, ou ao preparo instrucional dos licenciandos (LEAL et al, 2012). Como ocorre a formação destes futuros docentes (PEREYRA, 2013)? Será que os estudantes destes cursos são preparados para lecionar?

No decorrer deste texto procura-se discutir, em linhas gerais, como se desenvolve a formação dos professores de Sociologia e, dessa forma, inferir sobre os modelos formativos dos cursos de Ciências Sociais e as concepções de formação desses docentes, presentes nas instituições de ensino superior brasileiras.

Ao tratar da formação docente em Ciências Sociais é inevitável não apontar certa hierarquização que existe entre as duas modalidades do curso, mediante uma importância maior dada ao bacharelado frente à licenciatura, constituindo-se uma tradição de investigação profissional para os bacharéis e uma frágil formação docente para os licenciados, uma vez que, a princípio, o bacharelado seria a base curricular que define a profissão de sociólogo, enquanto que a habilitação em licenciatura possibilita exclusivamente a formação para professor. Diante dessas questões, propõe-se refletir sobre algumas visões bifurcadas que ainda colocam em lados opostos licenciatura e bacharelado, ensino e pesquisa, prática e teoria.

Busca-se também aqui apontar algumas possibilidades para a formação universitária inicial dos professores de Sociologia, partilhando-se das abordagens que consideram o estágio curricular dos cursos de licenciatura como um espaço privilegiado de encontro entre teoria e prática (PIMENTA; LIMA, 2006; PIMENTA, 2012; FREITAS, 2007), e daquelas que apontam o Programa Institucional de Bolsas de Iniciação à Docência (PIBID) como uma oportunidade de diálogo entre os conhecimentos teóricos do curso e as experiências práticas da profissão, ou entre o processo de formação inicial na universidade e a prática profissional docente nas escolas (ALMEIDA; ALVES, 2013; GONÇALVES, 2013; OLIVEIRA; BARBOSA, 2013).

\section{Modelos formativos e os novos desafios para a formação docente}


Ainda que se tenha indício sobre a formação de professores no século XVII ${ }^{4}$, ela só recebe alguma preocupação do Estado nacional no século XIX, na França, após a Revolução Francesa ter evidenciado a questão da instrução popular, e aberto espaço para a criação das Escolas Normais ${ }^{5}$. Já naquele momento, estas se diferenciavam entre Escolas Normais Superiores, responsáveis pela formação de professores de ensino secundário $^{6}$, e Escolas Normais Primárias, destinadas à preparação de docentes para $\mathrm{o}$ primário (SAVIANI, 2009).

No Brasil, a formação de docentes para o ensino secundário em cursos específicos foi proposta no final do século XIX (GATTI, 2010), com a criação das Escolas Normais brasileiras. Até o início dos anos 1930, os professores dessas escolas eram alguns profissionais liberais autodidatas (advogados, médicos e engenheiros), uma vez que é somente em meados dessa década que surgem as primeiras universidades ${ }^{7}$ com cursos para formação de bacharéis que, poucos anos depois, acrescentam um ano com disciplinas pedagógicas, para que o formando pudesse obter também o grau de licenciado, no intuito de habilitar docentes com formação específica para ministrar aulas no ensino secundário. Esse modelo ficou conhecido como "3+1” (FERNANDES; CUNHA, 2013; FREITAS, 2013; GATTI, 2010; PEREIRA, 1999), no qual o aluno cursava as disciplinas do bacharelado nos três primeiros anos e as disciplinas pedagógicas no quarto ano.

No entanto, esse desenho formativo que marcou por um longo tempo a formação docente no Brasil, e consequentemente os cursos de Ciências Sociais que habilitavam professores de Sociologia, apesar de persistir em algumas universidades brasileiras, já tende a ser superado, uma vez que "a legislação vem definindo os cursos de licenciatura plena como o lócus principal de formação docente" (HANDFAS, 2012, p. 26). Desde o

\footnotetext{
${ }^{4} \mathrm{O}$ primeiro estabelecimento de ensino destinado à formação de professores teria sido instituído por São João Batista de La Salle, em 1684, na cidade de Reims, com o nome de Seminário dos Mestres (DUARTE, 1986 apud SAVIANI, 2009, p. 143).

${ }^{5}$ A primeira instituição com o nome de Escola Normal foi instalada em Paris, em 1795 (SAVIANI, 2009, p. 143).

${ }^{6}$ Neste trabalho, as expressões "ensino secundário", "segundo grau" e "ensino médio" referem-se ao mesmo nível de ensino (àquele que antecede ao ensino superior) e são utilizadas de acordo com o contexto histórico e a legislação educacional vigorante.

${ }^{7}$ As primeiras universidades criadas no Brasil foram a de Manaus, em 1909, a de São Paulo, em 1911, e a do Paraná, em 1912, porém todas tiveram duração breve. Em termos legais, a primeira a ser criada por um decreto federal foi a Universidade do Rio de Janeiro, em 1920. Contudo, a Universidade de São Paulo (USP), fundada em 1934, foi a primeira universidade brasileira, em termos reais (FREITAS, 2013, p. 43 44). Na década de 1930 foram criadas também a Universidade do Distrito Federal (no Rio de Janeiro), em 1935, e a do Paraná, em 1938.
} 
início dos anos 2000, quando o Conselho Nacional de Educação (CNE) elaborou e aprovou as Diretrizes Curriculares Nacionais dos cursos de Ciências Sociais (2001), dois modelos formativos são majoritários nestes cursos: um que integra o bacharelado e a licenciatura (modalidade conjunta); e outro que possui duas modalidades distintas, isto é, dois cursos separados.

Contudo, a reintrodução da Sociologia como disciplina obrigatória do ensino médio e a implementação do Programa de Apoio a Planos de Reestruturação e Expansão das Universidades Federais (REUNI), vem abrindo caminho para a criação de novos cursos de licenciaturas em Ciências Sociais (PERRUSO; PINTO, 2012), inclusive com novas configurações. É o caso das licenciaturas em ciências humanas (com habilitação em Sociologia) ${ }^{8}$ oferecida pela Universidade Federal do Maranhão (UFMA), nos campi de Bacabal, Imperatriz e São Bernardo (OLIVEIRA, 2014a); e do bacharelado interdisciplinar em humanidades ${ }^{9}$, que ocorre na Universidade da Integração Internacional da Lusofonia Afro-Brasileira (UNILAB), funcionando nos municípios de Redenção, no estado do Ceará, e São Francisco do Conde, na Bahia.

Outra possibilidade de formação dá-se por meio da modalidade de Educação à Distância (EAD), que se expandiu principalmente a partir da criação da Universidade Aberta do Brasil (UAB) (LIMA, 2013), ainda que, em relação às Ciências Sociais a oferta dessa modalidade ${ }^{10}$ seja recente, tímida e incipiente (OLIVEIRA; BRUM, 2014), diante dos "limites impostos por essa modalidade de ensino ante as especificidades existentes no processo formativo das Ciências Sociais, no qual o acesso às obras de autores clássicos e contemporâneos, brasileiros e estrangeiros, mostra-se fundamental" (OLIVEIRA; BRUM, 2014, p. 46).

Têm surgido, sobretudo, depois da obrigatoriedade do ensino do conhecimento sociológico no nível médio, as chamadas licenciaturas em Sociologia ${ }^{11}$. Por um lado,

\footnotetext{
${ }^{8}$ A primeira parte do curso (oficialmente, nos três primeiros anos) promove uma formação "geral" na área das ciências humanas, e no último ano ocorre a habilitação na disciplina desejada: Filosofia, Geografia, História ou Sociologia.

${ }^{9}$ Nesse caso, cursa-se primeiramente um bacharelado de três anos em humanidades e no segundo ciclo faz-se a escolha para qual curso prosseguir: licenciatura em Pedagogia, em História, em Sociologia ou bacharelado em História, em Sociologia, em Antropologia, etc.

${ }^{10}$ A oferta de licenciaturas em Ciências Sociais ou Sociologia nessa modalidade ocorre nas seguintes instituições: Universidade Federal de Alagoas (UFAL), Universidade Federal de Viçosa (UFV), Universidade Estadual de Montes Claros (UNIMONTES), com a denominação de Sociologia na Universidade Federal de Santa Maria (UFSM), e na Universidade Federal do Amapá (UNIFAP) (OLIVEIRA; BRUM, 2014).

${ }^{11}$ É o caso da licenciatura em Sociologia da UFSM, ofertada na modalidade à distância (LIMA, 2013).
} 
isso pode sinalizar a busca por maior legitimidade e uma articulação mais direta entre disciplina escolar e científica (CARVALHO FILHO, 2014). Todavia, quando se faz um exame mais minucioso destes cursos, não significa que o modelo de formação docente varia tão significativamente; ele tende a reproduzir o curso de Ciências Sociais, modificando - em última instância - apenas o título. Além disso, são cursos que não seguem por completo as Diretrizes Curriculares Nacionais dos cursos de Ciências Sociais (2001), haja vista que estas definem a estruturação das matrizes curriculares dos mesmos pela integração entre as áreas que formam a identidade destes cursos (Antropologia, Ciência Política e Sociologia). Frente a isso, faz-se necessário uma avaliação mais detalhada do que seria licenciatura em Ciências Sociais ou em Sociologia e, mais do que isso, aprofundar a discussão sobre o que seria necessário para uma formação satisfatória do professor de Sociologia.

Boa parte dos cursos de licenciatura em Ciências Sociais criados a partir de 2008 encontra-se em instituições que já disponibilizavam o bacharelado, algo que indica um redirecionamento de esforços por parte do corpo docente dos departamentos desses cursos. Em razão disso, as licenciaturas começam a se colocar como um problema relevante, da mesma forma que a questão da formação do professor estabelece-se como uma demanda urgente a ser discutida e (re) pensada. Nesse sentido, a expansão de novos cursos não apenas lança novos modelos de formação de professores como também questões para os modelos já existentes. Não se pretende aqui fazer uma avaliação acerca dessas estruturas formativas nem apresentar qual delas seria a mais adequada. No entanto, algumas considerações podem ser lançadas.

\section{Novos modelos, velhas dicotomias}

Se aprofundarmos a discussão, podemos pôr uma questão em relevo: será que as licenciaturas de Ciências Sociais (assim como as demais) - e seus distintos modelos são realmente cursos de formação de professores stricto sensu? Em entrevista concedida a Lejeune Mato Grosso de Carvalho, Moraes (apud CARVALHO, 2011, p. 11) afirma que "os cursos de licenciatura não são verdadeiros cursos de formação de professores, mas um arremedo: predomina o bacharelado, ao qual a licenciatura aparece somente 
como um anexo, no fundo do quintal". Os cursos de Ciências Sociais são preparados para formar pesquisadores, ou seja, bacharéis, salvo algumas raras exceções.

Nesses cursos, às disciplinas teórico-metodológicas de formação específica são agregadas outras disciplinas, muitas vezes de caráter monográfico - variações, desenvolvimento e aprofundamento de temas e teorias decorrentes das primeiras, ou certo desdobramento das Ciências Sociais, não raramente definido a partir de objetos específicos. A esse eixo de disciplinas básicas e metodológicas acrescenta-se algumas de caráter complementar (Filosofia, História, Economia, Cultura Brasileira, por exemplo). Constitui-se, dessa forma, um quadro disciplinar bastante amplo de cunho bacharelesco; isso que é entendido, na maioria dos casos, como sendo a "sólida" formação.

Por sua vez, a formação de professores, chamada muitas vezes - senão sempre de a parte pedagógica reduz-se a um mínimo de disciplinas. São cerca de cinco, variando um pouco para mais ou para menos: duas didáticas; uma ou duas psicologias da educação; uma de legislação educacional; além dos estágios supervisionados e/ou práticas de ensino.

Mesmo nas universidades onde já existem dois cursos distintos, o pesquisador ainda é posto em evidência, em detrimento da figura do docente, uma vez que a grande maioria das disciplinas é dita do bacharelado e são poucas as voltadas para a licenciatura. Além disso, como ressalta Freitas (2013, p. 248), no caso do curso de Ciências Sociais

Também predomina uma valorização entre os docentes que lecionam as disciplinas de conteúdos específicos do curso, no bacharelado, em relação daqueles que lecionam as disciplinas de conteúdos pedagógicos voltados para a licenciatura. Se entendermos essa relação entre os docentes do campo acadêmico e do campo escolar, o prestígio dos primeiros em relação aos segundos é maior, assim como a hierarquia e o distanciamento [sic].

Até mesmo os cursos "exclusivamente" de licenciatura, seja pelas suas matrizes curriculares, seja pelas propagadas competências e habilidades, não têm uma orientação clara para a formação de professores. As estruturas curriculares mostram que ainda há o predomínio de uma tendência bacharelesca, na qual uma maior preocupação com uma sólida formação teórica fica evidente. Há aí um questionamento ou mesmo certo preconceito sobre o que seria essa formação de professores; ainda se persiste a ideia de 
que é fundamental se conhecer o conteúdo - e isso seria o básico para ser professor. Argumenta-se que os bacharéis são os únicos detentores do conhecimento científico, pois seriam estes que de fato desenvolvem pesquisas. Dessa forma, a condição de sociólogo se impõe (antecede) à do professor, e a formação do bacharelado imobiliza as possibilidades de adequações curriculares. Em outros termos, a condição de professor parece que é subordinada pela condição de sociólogo, na medida em que este se vê como detentor de um conhecimento especializado (TAKAGI, 2013).

Nesse sentido, o único profissional reconhecido, legal e socialmente, seria o sociólogo, pois formar-se para ser professor da educação básica representa ausência de profíssão - este seria uma espécie de "resíduo" do curso de Ciências Sociais. Os modelos de formação existentes, rigorosamente, são modelos que têm o bacharelado como o centro do processo formador. A licenciatura é vista como uma "alternativa de emergência"; daí emerge a percepção de que dar aula para o ensino médio é um demérito, um desvio na formação do cientista social. A partir disso, Moraes (2009, p. 20) sugere que devem ser feitas algumas mudanças de ponto de vista.

\footnotetext{
A primeira delas é que a formação do bacharelado não é suficiente, embora necessária, para garantir ao professor as condições para o exercício das atividades de ensino; a segunda é que se pode pensar a licenciatura, e não exclusivamente o bacharelado, também como um espaço de pesquisa
}

A pretensão histórica do bacharelado frente à licenciatura sempre foi uma questão problemática, na medida em que somente poucos graduados seguiam para a pós-graduação, isto é, para a carreira como pesquisador ou professor-pesquisador de nível superior. Mesmo com a consolidação da pós-graduação, boa parte dos alunos ainda possui apenas a graduação em Ciências Sociais e, dessa forma, seu principal campo de atuação profissional são (ou serão) as escolas de educação básica.

Nessa seara, Silva (2007, p. 421) aponta que "um dos problemas do ensino de sociologia nas escolas é o não compromisso dos cursos de ciências sociais com a formação de professores para o ensino médio". Haveria, dessa forma, uma subvalorização da licenciatura frente ao bacharelado. Além disso, observa que a "falta de investimento na formação do professor" apresenta-se como um empecilho à consolidação da disciplina na escola média. Esta afirmação é compartilhada por Handfas (2012), que destaca a dicotomia "ser professor/ser pesquisador", presente nos 
percursos formativos adotados por muitas instituições de ensino superior. A autora partilha da ideia de que os conteúdos curriculares dos cursos de graduação devem ser pensados com o intuito de superar essa dicotomia, entre a dimensão teórica e prática, na formação docente.

Uma das questões mais evidentes que se observa na maioria das graduações em Ciências Sociais é a falta de equilíbrio entre teoria e prática (os cursos tendem priorizar os conhecimentos teóricos em detrimento da prática). Como ressalta Takagi (2013, p. 217), "esse embate entre o teórico e o prático nas formações docentes é bastante recorrente, porém pouco se avança nessa questão em termos práticos”. Discutindo a esse respeito, Pavei (2008, p. 79) afiança que a licenciatura deve proporcionar uma interlocução entre a bagagem teórico-metodológica e a prática docente e, nesse sentido,

\begin{abstract}
Contemplar uma maior oferta de disciplinas voltadas para a formação de professores, especialmente ao ensino e ao fazer (se) docente de sociologia, isto é, com a articulação entre os saberes das Ciências Sociais e da Educação, por meio de questões de formação teórica com um olhar mais sociológico do processo educativo e do trabalho docente e também mais pedagógico do ensino da Sociologia, sem prejuízo das questões relacionadas à uma formação prática com maior interação e integração dos professores em formação e com as realidades escolares. Por todo o exposto, é imprescindível uma real manutenção da unidade teórico-prática no processo de formação de professores.
\end{abstract}

Com base em uma pesquisa realizada pela Fundação Carlos Chagas (FCC) sobre os currículos dos cursos de licenciatura em todo o Brasil, Gatti (2010, p. 1372) observou que nas ementas há

Um evidente desequilíbrio na relação teoria-prática, em favor dos tratamentos mais teóricos, de fundamentos, política e contextualização e que a escola, como instituição social e de ensino, é elemento quase ausente nas ementas, o que leva a pensar numa formação de caráter mais abstrato e pouco integrado ao contexto concreto onde o profissional-professor vai atuar.

Assim, verifica-se que a parte curricular que (teoricamente) destina-se ao desenvolvimento de habilidades profissionais indispensáveis para a atuação nas salas de aula é bastante reduzida, e que a relação teoria-prática mostra-se comprometida. Presume-se que o fato das disciplinas pedagógicas ainda serem ministradas por professores do departamento de Educação é um dos empecilhos à fluidez desta relação e para a articulação entre ensino e pesquisa, assim como para uma formação mais 
específica (própria) dos professores de Sociologia. Postula-se que se houvesse um investimento dos departamentos de Ciências Sociais ou Sociologia na formação de profissionais com conhecimentos e habilidades específicos da área da educação, não somente a relação entre teoria e prática, como também entre ensino e pesquisa, bacharelado e licenciatura dar-se-ia de maneira mais harmoniosa.

Umas das grandes questões que se apresentam para as licenciaturas em Ciências Sociais é definir quais conteúdos e metodologias devem ser lecionados nas disciplinas pedagógicas, para que, quando forem adotados na educação básica sejam adequados à realidade escolar e façam sentido aos alunos desse nível de ensino.

Geralmente privilegia-se uma sólida formação teórica-conteudista do graduando, e os conhecimentos didáticos-pedagógicos (diretamente relacionados à prática docente) dispõem de pouco espaço no currículo, como se bastasse “dominar bem" os conhecimentos específicos da área para ser professor; como se fosse suficiente ter ou desenvolver algumas habilidades pessoais: aquele que é professor (da educação básica) seria alguém que possui dom, talento ou vocação para a docência ou que já estava predestinado para isso. Por esse motivo, a formação didático-pedagógica seria desnecessária ou pouco relevante, já que não irá fazer falta (FREITAS, 2013).

Todavia, para ser professor não basta apenas dominar o conteúdo, ou dispor de vocação, talento ou dom para ensinar, pois no processo de transmissão do conhecimento sociológico é necessário que se saiba adequar os conhecimentos teóricos-metodológicos adquiridos na formação inicial com as "situações reais do cotidiano escolar" (OLIVEIRA, 2007). "É preciso que se conceba a docência como um ofício que requer formação profissional, com conhecimentos e saberes específicos" (FREITAS, 2013, p. 252). E para isso, é fundamental que a licenciatura não seja posta em um degrau abaixo do bacharelado, mas percebida como uma modalidade plenamente capaz de conjugar ensino e pesquisa, prática e teoria.

\section{Espaços possíveis de formação do professor}

Ao instituir a duração e a carga horária dos cursos de formação de professores da educação básica (2001), o CNE propôs, entre outras medidas, uma nova redistribuição 
da carga horária do estágio ${ }^{12}$ (ZAN, 2011), abrindo-se a possibilidade de ampliar o espaço da prática (do fazer docente) no processo de formação dos futuros professores. A partir de então

\begin{abstract}
O estágio curricular adquire, portanto, um outro sentido, tanto para o curso de licenciatura, quanto para os professores e estudantes. De um modo geral, o estágio curricular sempre foi tratado como a fase final dos cursos de licenciatura, no qual os futuros professores tomavam contato com a realidade em que pretendiam exercer a profissão. (FREITAS, 2007, p. 4).
\end{abstract}

O estágio curricular constitui uma parte indispensável e basilar no processo formativo dos licenciandos, pois apresenta-se como um espaço de diálogo e produção de conhecimento, momento em que teoria e prática se encontram, (PIMENTA; LIMA, 2006; PIMENTA; 2012), ou seja, o estágio também pode ser considerado como uma ocasião oportuna de realização de pesquisa. Dessa forma, "debater o Estágio Supervisionado certamente nos remete a questões pertinentes a todas as licenciaturas, uma vez que, talvez, o maior desafio nesse tipo de formação é a articulação entre a teoria e a prática" (OLIVEIRA, 2014b, p. 203).

O estágio é o momento em que o aluno em formação entra em contato com a realidade cotidiana escolar, e por meio do qual ele começa a observar e desenvolver uma prática docente. $\mathrm{O}$ estagiário não deve observar apenas a regência do professor em sala de aula, mas os diversos momentos em que a aula é concebida. Nesse sentido,

\begin{abstract}
O estágio possibilita que esse professor conheça não apenas a prática docente na Sociologia, como também os momentos que a antecedem: o planejamento, a seleção dos conteúdos, das metodologias, dos materiais utilizados, bem como viabiliza a percepção do hiato que se estabelece entre o planejado e o executado em sala de aula (OLIVEIRA, 2014b, p. 206).
\end{abstract}

O licenciando não deve centrar seu relato apenas na observação da prática docente, mas atentar-se também para quais recursos didáticos despertam maior interesse dos alunos de Sociologia, quais leituras são mais atrativas, quais temas e conteúdos prendem a atenção dos alunos. Ele deve está atento à relação entre docente, discente e conhecimento escolar (OLIVEIRA; BARBOSA, 2013).

\footnotetext{
${ }^{12}$ Antes da Lei de Diretrizes e Bases da Educação Nacional (LDBEN) de 1996 era de 120 horas; passouse para 300 horas com a referida lei; e com as DCN de 2002, ampliou-se para 400 horas.
} 
O estágio também possibilita a troca de experiência entre o professor regente e o formando, haja vista que, em muitas escolas há somente um professor de Sociologia, o que provoca o isolamento desse profissional (por não se ter uma comunidade de professores da disciplina no interior das unidades escolares e nem fora delas). Mesmo que o professor regente não possua formação inicial em Ciências Sociais, é possível que ele estabeleça essa relação com o estagiário, na medida em que expõe a sua experiência profissional na área, suas dificuldades, desafios e percepções acerca da prática docente. De tudo,

\begin{abstract}
O que se coloca é como pensar o processo de transposição didática da ciência de referência para a realidade escolar, considerando que não há um automatismo entre a Sociologia enquanto disciplina acadêmica e enquanto disciplina escolar, uma vez que suas características ontológicas defrontam-se com os elementos contingenciais em meio aos quais se desenvolve a prática pedagógica. (OLIVEIRA, 2014b, p. 204).
\end{abstract}

Nesse sentido, o estágio curricular é uma parte importante da formação do licenciando, na medida em que, para muitos (ou boa parte) este é o único momento que o professor em formação pode fazer a articulação entre teoria e prática. Para tanto, os cursos que formam os professores de Sociologia devem procurar encurtar a distância entre o ensino superior e o básico, possibilitando uma maior inserção do licenciando em seu (futuro) espaço de trabalho.

Outra possibilidade essencial para a formação de professores é o PIBID. Criado em 2007 pelo MEC, e instituído por meio da Coordenação e Aperfeiçoamento de Pessoal de Nível Superior (CAPES) e do Fundo Nacional de Desenvolvimento da Educação (FNDE), o programa concede bolsas de iniciação à docência a alunos de licenciatura plena das instituições federais e estaduais de educação superior, ${ }^{13}$ que possuem parceria com escolas de educação básica da rede pública de ensino.

Um dos principais objetivos do PIBID é adiantar a inserção dos estudantes (futuros professores) nas salas de aulas, para que desenvolvam atividades didáticopedagógicas sob orientação de um docente da universidade e de um professor da escola. A partir disso, o programa proporciona mudanças na relação entre universidade e escola

\footnotetext{
${ }^{13}$ Vale ressaltar que o PIBID, mesmo sendo um programa de grande abrangência, não contempla todas as licenciaturas, mesmo aquelas das universidades públicas. Portanto, ainda que este texto não detalhe o alcance e extensão do programa, alerta-se para a não generalização das informações. Essa observação também vale para as licenciaturas em Ciências Sociais ou Sociologia.
} 
básica (ALMEIDA; ALVES, 2013), no que diz respeito à formação docente, sobretudo, por meio da associação entre teoria e prática. A ideia é construir uma relação mais horizontal entre o mundo acadêmico e o escolar. A partir do PIBID, o contato dos graduandos com a escola pública não se restringe apenas ao momento derradeiro de sua formação (estágio curricular), pois desde os primeiros períodos do curso, por meio de diferentes atividades planejadas e projetos, os licenciandos já entram em contato com as diversas situações do cotidiano escolar.

Dessa forma, o programa possibilita um diálogo entre os conhecimentos teóricos do curso e as experiências práticas da profissão docente. Isso permite uma aproximação entre o processo de formação inicial na universidade com a prática profissional docente nas escolas e contribui para que os alunos vão incorporando elementos importantes para a constituição de uma identidade profissional - de professor (OLIVEIRA; BARBOSA, 2013). O programa tem contribuído também para o fortalecimento da licenciatura, pois possibilita um número muito maior de chances de permanência dos alunos no curso.

É inegável que o PIBID tem possibilitado muito mais que a constituição de um espaço institucional para as discussões sobre as questões que perpassam as licenciaturas no interior das universidades (incluindo aí a formação dos professores), sobre o ensino de Sociologia no ensino médio e o lugar dessa disciplina nesse nível de ensino. O programa proporciona também o contato mais direto e prolongado do graduando com a realidade da educação básica, algo que não era possível somente com o estágio curricular supervisionado (GONÇALVES, 2013).

Para além disso, ao colocar o ensino de Sociologia como objeto de estudo e reflexão, os bolsistas do PIBID (e também seus professores coordenadores e supervisores) incrementam a produção de trabalhos científicos que fortalecem a área da Sociologia da educação. São pesquisas sobre formação de professores, materiais didáticos, metodologias de ensino, entre outras. Nesse sentido, por meio do programa, há também a possibilidade de pesquisa, demonstrando que essa atividade não se restringe somente ao bacharelado, mas pode e deve estar presente nos cursos de formação de professores.

\section{Considerações finais}


$\mathrm{O}$ atual momento da Sociologia como disciplina escolar exige transformações nos modelos - aparente e historicamente dualistas - formativos dos cursos de Ciências Sociais. Nesse novo contexto sócio histórico em que se insere a Sociologia, discutir sobre a formação do professor dessa disciplina é bastante oportuno.

Sem a pretensão de esgotar a discussão sobre o tema proposto, mas muito mais com o intuito de estimular a reflexão e propor outras possíveis pesquisas nesta perspectiva, este trabalho possibilitou conhecer e aclarar algumas questões em torno da formação inicial de professores de Sociologia, e identificar as relações entre a formação bacharelesca e a licenciatura, apontando para uma subvalorização desta frente à primeira. Percebeu-se uma fragmentação na formação dos licenciandos, o que sinaliza frágil preparação para a docência no ensino básico.

Uma das explicações para a pouca preocupação dos cursos de Ciências Sociais com a formação do professor pode estar nas inconstantes presenças da Sociologia enquanto disciplina no ensino médio, o que faz com que o campo efetivo de atuação do licenciado na área seja recente. Além disso, em função da precariedade e a baixa remuneração do trabalho docente, são poucos que enxergam nele um espaço de atuação de um cientista social.

É notório que os desafios a serem superados ainda são muitos, para que se possa constituir uma sólida formação docente. Entretanto, as possibilidades que se apresentam para superar essas lacunas são estimulantes, sobretudo, no que concerne ao estágio supervisionado de licenciatura e ao PIBID. Aquele é um espaço privilegiado para formação dos alunos de licenciaturas em Ciências Sociais, momento fecundo para o futuro professor articular os conhecimentos teóricos com a prática pedagógica. Por sua vez, o PIBID tem possibilitado muito mais que a constituição de um espaço institucional para as discussões sobre formação de professores, ao proporcionar o contato direto do graduando com a realidade da escola média, algo que não era plenamente possível somente com o momento do estágio.

\section{Referências}

ALMEIDA, R. de O; ALVES, J. T. Ensino de Sociologia na escola básica: experiência do PIBID na formação de professores. In: GONÇALVES, D. N. Sociologia e juventude no ensino médio: formação, PIBID e outras experiências. Campinas: Pontes Editores, 2013. 
BRASIL. Conselho Nacional de Educação. Conselho Pleno. Resolução CNE/CP, 1 de 18 de fevereiro de 2002. Institui Diretrizes Curriculares Nacionais para a Formação de Professores da Educação Básica, em nível superior, curso de licenciatura, de graduação plena. Disponível em: < http://portal.mec.gov.br/cne/arquivos/pdf/rcp 01_02.pdf $>$. Acesso em: 23 out. 2015.

BRASIL, Ministério da Educação. Parecer CNE/CP n²8/2001, de 02 de outubro de 2001. Dá nova redação ao Parecer CNE/CP 21/2001, que estabelece a duração e a carga horária dos cursos de formação de professores da educação básica, em nível superior, curso de licenciatura, de graduação plena.

BRASIL. Parecer CNE/CES $n^{0}$ 492/2001. Diretrizes Curriculares Nacionais dos cursos de Filosofia, História, Geografia, Serviço Social, Comunicação Social, Ciências Sociais, Letras, Biblioteconomia, Arquivologia e Museologia. Diário Oficial da União, Brasília, 9 de jul. 2001.

BRASIL. Lei de Diretrizes e Bases da Educação Nacional. Lei no 9394, de 20 de dezembro de 1996. Estabelece as diretrizes e bases da educação nacional. Brasília, DF, 1996.

BRASIL. Lei n. ${ }^{\circ}$ 11.648, de 2 de junho de 2008. Altera o art. 36 da lei n. ${ }^{\circ} 9.394$, de 20 de dezembro de 1996, que estabelece as diretrizes e bases da educação nacional, para incluir a Filosofia e a Sociologia como disciplinas obrigatórias nos currículos do ensino médio. Diário Oficial da União, Brasília, 3 de jun. 2008.

CARVAlHO, L. M. G. X. de. Ensinar Sociologia. Entrevista com Amaury César Moraes. Revista Sociologia - Ciência \& Vida. Ano IV, $33^{a}$ ed. São Paulo: Editora Escala, 2011.

CARVALHO FILHO, J. L. de. O Ensino de Sociologia como problema epistemológico e sociológico: relação entre Brasil e França. Educação \& Realidade. Porto Alegre, v. 39 , n. 1,2014 , p. 59-80.

CUNHA, M. I. da. O tema da formação de professores: trajetórias e tendências do campo na pesquisa e na ação. Educ. Pesqui., São Paulo: Aheadofprint, 2013, p. 1-17.

FERNANDES, C. M. B.; CUNHA, M. I. da. Formação de professores: tensão entre discursos, políticas, teorias e práticas. Inter-Ação. Goiânia, v. 38, n. 1, 2013, p. 51-65.

FREITAS, L. K. G. de. Currículo e formação do docente no curso de Ciências Sociais/UFPA: configurações, continuidades e rupturas (1963-2011). Tese de doutorado (Programa de Pós-Graduação em Educação do Instituto de Ciências da Educação da Universidade Federal do Pará). Belém, 2013, 308p.

FREITAS, R. A. de. Estágio Supervisionado: espaço privilegiado de formação na licenciatura em Ciências Sociais. In: XIII Congresso Brasileiro de Sociologia, 2007. Anais. Sociedade Brasileira de Sociologia, Recife, 2007. 
GATTI, B. A. Formação de professores no Brasil: características e problemas. Educação e Sociedade. Campinas, v. 31, n. 113, 2010, p. 1355-1379.

GONÇALVES, C. A. A Experiência do Pibid na Formação do Professor de Sociologia. EntreVer. Florianópolis, v. 3, n. 4, 2013, p.44-51.

HANDFAS, A. Formações dos professores de Sociologia: um debate em aberto. In: HANDFAS, A; MAÇAÍRA, J. P. Dilemas e perspectivas da Sociologia na educação básica. Rio de Janeiro: E-papers, 2012.

HANDFAS, A; MAÇAÍRA, J. P. O estado da arte da produção científica sobre o ensino de sociologia na educação básica. BIB. São Paulo, n. 74, 2014, p.43-59.

LEAL, S. et al. Formação e saberes docentes para o ensino de Sociologia nas escolas: reflexões sobre a licenciatura em Ciências Sociais da Universidade de Brasília-UNB. In: Anais do $3^{\circ}$ Encontro Estadual de Ensino de Sociologia (ENSOC). Rio de Janeiro, 2012.

LIMA, L. B. de. A Universidade Aberta do Brasil e a formação do professor de Sociologia à distância. Dissertação de mestrado - curso de Pós-Graduação em Educação da Universidade do Estado do Rio de Janeiro. Rio de Janeiro, 2013, 100p.

MORAES, A. C. Desafios para a implantação do ensino de sociologia na escola média brasileira. In: HANDFAS, A; OLIVEIRA, L. F. de (orgs.). A Sociologia vai à escola: história, ensino e docência. Rio de Janeiro: Quartet, 2009.

NEUHOLD, R. dos R. Sociologia do ensino de sociologia: os debates acadêmicos sobre a constituição de uma disciplina escolar. 2014. Tese (Doutorado em Educação) Universidade de São Paulo - USP, São Paulo, 2014.

OLIVEIRA, D. M. de. A prática pedagógica dos professores de Sociologia: entre a teoria e a prática. Dissertação de mestrado (Universidade Estácio de Sá). Rio de Janeiro, 2007, 111p.

OLIVEIRA, A; BARBOSA, V. S. L. Formação dos Professores de Ciências Sociais: desafios e possibilidades a partir do Estágio e do PIBID. Inter-Legere, n. 13, 2013, p. 140-162.

OLIVEIRA, A.; BRUM, C. K. Ciências Sociais a distância: apontamentos sobre os desafios da formação de professores no Brasil. O público e o privado, n. 24, 2014, p. $29-49$.

OLIVEIRA, A. A Formação de professores de Ciências Sociais frente às políticas educacionais. Crítica e Sociedade: revista de cultura política. Uberlândia, v. 3, n. 2, 2013, p. 132-152.

A formação inicial de professores de Sociologia no nordeste: alguns breves apontamentos. Pesquiseduca. Santos, v. 6, n. 12, 2014a, p.285-299. 
- Desafios e Singularidades do Estágio Supervisionado na Formação de Professores de Ciências Sociais. Educação: Teoria e Prática. Rio Claro, vol. 24, n.47, p. 195-216, set-dez. 2014b.

O Ensino de Antropologia na formação de Professores de Ciências Sociais. Café com Sociologia. Vol.4, n. 2, p. 84-97, maio-jul. 2015.

PAVEI, K. Reflexões sobre o ensino e a formação de professores de Sociologia. Dissertação de mestrado (Programa de Pós-graduação em Educação da Universidade Federal do Rio Grande do Sul). Porto Alegre, 2008, 123p.

PEREIRA, J. E. D. As licenciaturas e as novas políticas educacionais para a formação docente. Educação \& Sociedade, ano XX, n. 68, 1999, p. 109-125.

PEREYRA, D. A formação de professor de Sociologia na Argentina - desafios e experiências institucionais. In: GONÇALVES, D. N. Sociologia e juventude no ensino médio: formação, PIBID e outras experiências. Campinas: Pontes Editores, 2013.

PERRUSO, M. A; PINTO, N M. Sobre a Sociologia no Ensino Médio e uma experiência de licenciatura em Ciências Sociais. In: FIGUEIREDO, A. V. de; OLIVEIRA, L. F. de; PINTO, N. M. (orgs.). Sociologia na sala de aula: reflexões e experiências docentes no Rio de Janeiro. Rio de Janeiro: Imperial Novo Milênio, 2012.

PIMENTA, S. G. O Estágio na Formação de Professores: unidade teoria e prática? São Paulo: Cortez, 2012.

PIMENTA, S. G; LIMA, M. S. L. Estágio e docência: diferentes concepções. Poíesis, vol. 3, números 3 e 4, 2006, p. 5-24.

SAVIANI, D. Formação de professores: aspectos históricos e teóricos do problema no contexto brasileiro. Revista Brasileira de Educação, v. 14, n. 40, 2009.

SILVA, I. L. F. A sociologia no ensino médio: os desafios institucionais e epistemológicos para a consolidação da disciplina. Cronos, Natal, v.8, n. 2, 2007, p. 403-427.

TAKAGI, C. T. T. Formação do professor de Sociologia do ensino médio: um estudo sobre o currículo do curso de Ciências Sociais da Universidade de São Paulo. Tese de doutorado (Faculdade de Educação da Universidade de São Paulo). São Paulo, 2013, $232 p$.

VELLOSO, R. V. Desafios para a formação de professores nas universidades públicas. Revista Eletrônica de Educação. São Carlos, SP: UFSCar, v. 6, n. 2, 2012, p.427-439.

ZAN, D. D. P. e. O Estágio na Formação do Professor de Sociologia. Cadernos CEDES. Campinas, vol. 31, n. 85, 2011, p. 449-458. 


\title{
Formação de professores de ciências sociais/sociologia: subsídios para o debate
}

Resumo: Este trabalho busca refletir sobre o tema da formação inicial de professores de Ciências Sociais/Sociologia. Em um primeiro momento, analisa brevemente os modelos formativos das licenciaturas em Ciências Sociais, na tentativa de extrair as concepções sobre a formação do professor de Sociologia da educação básica presentes em muitas instituições de ensino superior. Em seguida, retoma a discussão em torno dos binômios licenciatura versus bacharelado, ensino versus pesquisa, na medida em que a dicotomia "ser professor/ser pesquisador", presente nos percursos formativos adotados por muitas universidades, evidencia um desequilíbrio na relação entre teoria e prática. Por fim, aponta o estágio curricular supervisionado dos cursos de licenciatura como um espaço privilegiado de encontro entre teoria e prática, e o Programa Institucional de Bolsas de Iniciação à Docência (PIBID) como uma oportunidade de conexão entre o processo de formação inicial na universidade e a prática profissional docente.

Palavras-chave: Formação de Professores; Modelos Formativos; Desafios; Espaços de Formação

\section{Social sciences/sociology teachers formation: subsidies for debate}

\begin{abstract}
This work aims to reflect on the theme of initial formation of Social Sciences/Sociology teachers. At first, briefly analizes the formative models of the licenciatura in Social Sciences, in an attempt to extract the conceptions about the formation of Sociology teachers at the basic education that can be found in many higher education institutions. After that, resumes the discussion about the binomial bachellor degree versus degree, teaching versus research, in means that the dichotomy "being a teacher / being a researcher," present in the formative percourse adopted by many universities, shows an imbalance in the relationship between theory and practice. At the end, points the supervised traineeship of licenciature courses as a privileged place of encounter between theory and practice, and the Programa de iniciacao à docencia (PIBID) as a opportunity of connection between the initial formation process at the university and teaching professional practice.
\end{abstract}

Keywords: Teachers Formation; Formative Models; Challenges; Spaces of Formation

Recebido em: 31 de agosto de 2015.

Aceito para publicação em: 27 de outubro de 2015. 